\title{
Water Fluoridation: a Response to Critics in Australia and New Zealand
}

\author{
Brian A. Burt, BDS, MPH, PhD \\ Eugenio D. Beltran, DDS \\ Program in Dental Public Health \\ School of Public Health \\ The University of Michigan \\ Ann Arbor, MI 48109-2029
}

public policy. The arguments presented by Diesendorf and Colquhoun will be examined in detail, and the role of fluoride in the caries decline discussed.

\section{Diesendorf's Challenge}

Diesendorf's report on the nature of the caries decline aroused considerable interest, at least partly because it was published in Nature. Diesendorf's principal argument is that the caries decline cannot be attributed to water fluoridation, and only partly to other uses of fluoride. He suggests as alternative hypotheses that the decline may stem from dietary changes, such as reduced consumption of sugar and increased consumption of whole grains, cereals, and nuts, and from possible changes in the immune system.

To support his argument, Diesendorf first quoted data from Lawson et al. (10) who reported that the proportion of Sydney schoolchildren aged 5-12 with "naturally sound" teeth, by which the authors meant caries-free, increased from 3.8 percent in 1961 to 20.2 percent in 1967 to 28 percent in 1972 . Because Sydney fluoridated in 1968, Diesendorf concluded that these figures showed that the main reduction in caries had taken place before fluoridation began. There are strong doubts, however, about whether these data are sufficiently valid to support any trend analysis. Lawson et al. stated that the percentages in question were based on cursory dental screenings to identify children in need of treatment and did not follow a standardized protocol. In addition, the screenings were conducted only in selected schools in a " . . white-collar area, and were never intended to be a representative sample of Sydney schoolchildren." Further doubt is cast on the validity of the data from Lawson et al. by Craig, in a personal communication (August 1986), who compared data from more standardized surveys (11-13) to show that DMF rates in both Sydney and Canberra, the federal capital, were essentially stable from the mid1950s through the mid-1960s, when neither city had fluoridated water.

Sutton (14), a long-time opponent of fluoridation, had earlier criticized the paper by Lawson et al., and much of Sutton's letter is echoed by Diesendorf. Both Sutton and Diesendorf castigate a later report by Burton et al. (13) that examined declines in caries experience among Sydney schoolchildren over a 19-year period, for not using the data of Lawson et al. in their compari-
This study was supported by a contract from the Dental Disease Prevention Activity, Centers for Disease Control, Atlanta, Georgia. Send correspondence and reprint requests to Dr. Burt. Manuscript received: 12/29/87; returned to author for revision: $2 / 26 / 88$; accepted for publication: $4 / 20 / 88$. 
sons. Diesendorf concluded that the report by Lawson et al. had been ignored because it was " . . . a source of embarrassment."

The 1978 paper by Lawson et al. had serious limitations as a scientific study, and seemed to be receiving more attention than it deserved. While Diesendorf made too much of the dubious prevalence data from Lawson et al. to support his case, Lawson et al. should not have cautioned that their results were ". . . summary data not to be used for detailed studies," and then claimed that they demonstrated "... a modern triumph of preventive health care." A purported increase in caries-free 5-12-year-old children from 3.8 percent to 20.2 percent in just six years does seem rather precipitous over that age range, and could stem from sampling or examiner variation. While no one seriously doubts that the oral health of the children concerned did improve considerably during the 1961-72 period, these unstandardized data from haphazard samples cannot be used to support cause-and-effect conclusions.

\section{"The political overtones of the public debate on water fluoridation, and the often acrimonious personal attacks that accompany it, long ago over- whelmed true scientific debate in the public policy arena."}

Diesendorf also presented data from surveys conducted in Sydney in 1954-55 (11) and in 1973 (15). Comparison of these surveys show that the DMFT of 13-14year-olds in Sydney dropped from 11.0 to 6.7 during that period, a change Diesendorf accepted as further evidence that caries was in decline before fluoridation began in 1968. But the 1973 data cannot support that contention, since four years' postfluoridation is ample time for substantial caries preventive benefits to become evident $(16,17)$.

Later in his paper, Diesendorf reports from studies of caries declines among children in the Netherlands (18) and England (19). The studies in question came from Kalsbeek and from Anderson and colleagues, respectively, and were presented at the First International Conference on the Declining Prevalence of Dental Caries, held in Boston in 1982. Commenting on Kalsbeek's finding that caries in selected communities in the Netherlands had declined some 50 percent between 1970 and 1980, Diesendorf states:

Kalsbeek also reviewed the use of fluoride tablets and toothpaste and concluded from the data that "factors other than the effects of different fluoride programs must play a role."

Diesendorf goes on to state that "... the Dutch review suggest(s) that fluoride tablets may not be im- portant ... [and] provides evidence against fluoride toothpaste. ..."

Kalsbeek's actual comments on the observed decline in the Netherlands were:

Taking all forms of fluoride application (including tablets and dentifrices) together, it is clear that these must have had an effect on the caries experience of the children. How far this factor can explain the assumed caries reduction is uncertain.

The data from Tiel . . . reveal that all factors taken together now have more effect than did water fluoridation alone in 1968, especially on the percentage of caries-free children. Since water fluoridation probably provides the maximum effect of fluoride, one can conclude that, at the moment, factors other than the effects of different fluoride programs must play a role.

Later, in his conclusion, Kalsbeek states:

The increased use of fluoride in different forms was undoubtedly a causative factor for the reduced caries experience. However, other as-yet-unknown factors may play a role.

Essentially, Kalsbeek is saying that the observed decline must be at least partly attributed to the various uses of fluoride, but that unspecified other factors could be involved. Kalsbeek's statements conform with other current views on reasons for the caries decline (20).

At the same Boston conference in 1982, Anderson et al. presented data from several areas in the British Midlands to demonstrate a substantial decline in caries in children between 1964 and 1980. Anderson et al. tried to pinpoint when the decline began; to do so, they employed previously unpublished data collected by the Gloucestershire Community Dental Service. Commenting on these data, Diesendorf states:

The authors . . . point out that sales of fluoride toothpaste in the United Kingdom were less than $5 \%$ of total sales in 1970 , but rose to more than $95 \%$ of sales in 1977. They quote unpublished data from unfluoridated parts of Gloucestershire, collected from 1964 onwards, which show substantial improvements in children's teeth before the use of fluoride toothpaste became significant.

Anderson et al. provide details of temporal fluctuations in the caries experience of Gloucestershire children between 1964 and 1980, using several measures of caries experience. What they actually say about fluoride toothpaste is:

In three of the four distributions described, marked improvements can be observed commencing in 19745 , which would support an association between the increasing use of fluoride toothpaste and a reduction in caries prevalence. However, this is not the only point at which a change took place. The incisors of the 14-year-olds were improving during the late 1960 s, and the improvement in the five-year-olds, 
with high caries rates, started in 1971. These changes at different times indicate that other factors must also have been involved. Throughout the whole period, there has been an increasing use of dental health education in the Gloucestershire schools, and an active campaign against the misuse of vitamin syrups was conducted in 1966-7.

Anderson et al. also state that their research demonstrates ". . . the difficulty of trying to undertake analytical epidemiology from information which was collected for descriptive purposes," implying that the specific values from this data set should not be taken too literally. Like Kalsbeek, Anderson et al. concluded that much of the caries decline must be attributed to fluoride, but that there are likely to be other causative factors. Again, this conclusion does not differ from current views in dental research.

Diesendorf also adheres to the view that fluoridation is effective only because it is incorporated into developing enamel, a view that is long outdated (21-23). Diesendorf used data from the Australian town of Tamworth, which showed a steady decline in caries in children following fluoridation of Tamworth's water in 1963 , to argue that the continuing decline could not be due to fluoridation. He stated, in reference to the Tamworth data:

... it has been claimed ever since the commencement of fluoridation that the maximum possible benefits from fluoridation are obtained in children who have drunk fluoridated water from birth. Six-yearolds would have done this by 1969 , when, according to the published data, they had a DMFT index of 0.6 .

The further reduction in caries in optimally exposed 6-year-olds, observed in years following 1969, cannot be due to fluoridation.

While it cannot be demonstrated that further decreases in DMF values were specifically due to fluoridation, it is highly likely that they were due to fluoride: the effect of fluoridated water combined with the increasing use of fluoride toothpaste over this period would have acted to reduce caries experience steadily in the community.

\section{Questions from New Zealand}

The efficacy of fluoridated water in improving children's dental health in New Zealand has been questioned by Colquhoun (4-9). In an earlier report, Colquhoun (pronounced Co-houn), then a principal dental officer for the Auckland Health District, had concluded that fluoridation of Auckland in 1966 had narrowed the gap between dental need and dental treatment in all social classes, but especially in the lower classes (24). A similar conclusion had been reached by others before Colquhoun's report $(25,26)$ and after it $(27,28)$, though some recent reports did not find social class differences following fluoridation (29-33). Interpreting this body of literature is not easy because of national differences in classifying social rank, and possibly because of the different social/political viewpoints of some authors.
In his later works, however, Colquhoun reached very different conclusions. Using data from the same source, official health department statistics, four of these papers in 1984-85 concluded that fluoridation has been ineffective in preventing caries in New Zealand, while the fifth (5) was a review of this argument. His most recent work (9) challenged the credibility of the pioneering Napier-Hastings fluoridation project in New Zealand during the 1950s. Much of the argument in this 1986 report relates to alleged changes in diagnostic standards during the study, similar to those made by Sutton (34) with reference to the Grand Rapids-Muskegon project, and, as specific criticism of a specific study, will not be discussed here.
"Diesendorf's principal argument is that the caries decline cannot be attributed to water fluoridation, and only partly to other uses of fluoride. He suggests as alternative hypotheses that the de- cline may stem from dietary changes, such as reduced consumption of sugar and increased consumption of whole grains, cereals, and nuts, and from possible changes in the immune system."

Colquhoun's principal argument (6) is that the oral health of children aged 3-13 in a nonfluoridated, lowerclass district of Auckland had improved between 1966 and $1981-82$ to the point where it was better than oral health of children of the same social class in fluoridated districts. According to these data, oral health within the fluoridated areas of Auckland seemed to have improved equally among all social classes between 1966 and 1981. Colquhoun's data showed that the 1981 rate of permanent fillings per child in fluoridated districts of Auckland ranged from 0.25 in the highest social rank area to 0.79 in the lowest, while the nonfluoridated area (Onehunga), which was classified as being of the lowest social rank, had a rate of 0.34 . He concluded that while overall improvement in oral health had occurred, oral health was correlated with social class, but not with fluoridation.

Some special features of dental care for schoolchildren in New Zealand are worth noting here. The School Dental Nurse plan, established in 1921, is an imaginative approach to dental care for children that has now been adopted by a number of other countries in the region $(35,36)$. Deployment of dental nurses brings routine dental care, educational attention, and individual fluoride therapy to virtually all primary schoolchildren in the country, and to a high proportion of pre-schoolchildren as well. One aspect of this high coverage, as Colquhoun pointed out, is that DMF 
scores in many localities are virtually all $F$, because practically no teeth are extracted and few lesions escape restoration. Treatment data collected by this efficient organization are likely to be reliable, though variations in diagnostic criteria are naturally to be expected.

But questions arise about the data in Colquhoun's presentations. One concerns the validity of comparing "social rank" of districts from a 1966 University of Auckland sociology study and the 1981 New Zealand census. The marked fluctuations in the numbers of dental clinics and children completing care in each social class area between 1966-74 and 1981 (6) seem unlikely to be due to the opening and closing of clinics over that period. When presented without explanation they raise the question of whether the social class boundaries in the 1966 study and the 1981 census were the same. If they were not, then Colquhoun's social rank comparisons are invalid (6).

A worse flaw came to light in a personal communication from Hunter (June 1987), at the time deputy director of the Dental Health Program in New Zealand. Hunter's review of Colquhoun's data showed that 38 percent of the 12-13-year-old children who attended school in Onehunga, the low social class area described by Colquhoun (6), actually lived in high social rank areas in Auckland, districts that received fluoridated drinking water. This confounding of residence and fluoride histories produced serious misclassifications and severely compromised Colquhoun's data, and hence his conclusions.

\section{"Colquhoun's principal argument is that the oral health of children aged 3-13 in a nonfluoridated, lower-class district of Auckland had improved between 1966 and 1981-82 to the point where it was better than oral health of children of the same social class in fluoridated districts."}

Colquhoun defended the validity of the "permanent fillings per child" measure on the basis of the unusual comprehensiveness of the New Zealand school dental system. But Hunter, in his personal commmunication, provided 1981 data from the 12 intermediate school clinics in the Auckland Health District to show that DMFT scores for 11-14-year-old children varied from 2.85 to 4.75 in different clinics. Even more important, the large variation in the rate of fillings per child per year was sufficient to question seriously this measure as a proxy for caries experience in Auckland.

There are several other issues that may be nothing more than reporting omissions, or that may be real weaknesses. First, Colquhoun (6) used aggregate data for all ages 3-13, so any variation in age distributions between the different social rank areas could have af- fected results. It is likely, for example, that a higher proportion of pre-schoolchildren presented for care in the higher social rank areas than in the lower. If so, the measure of permanent fillings per child would naturally be depressed in the higher social rank areas. Even the alternative measure of "total fillings and extractions per child," which included the primary dentition, would have been depressed by a high proportion of younger children. Second, apart from a comment that all children in nonfluoridated areas received six-month topical fluoride applications while only "at risk" children received them in fluoridated areas, the potentially different uses of fluoride toothpaste and supplements were not pursued. Third, there was mention (4) of the high proportion of Maoris and Pacific Islanders in the lower social class areas, but any potential bias from ethnic differences in caries experience and attitudes to oral health was not pursued.

Colquhoun made only passing reference to other studies, but recent reports from New Zealand show that DMF scores have fallen in both fluoridated and nonfluoridated areas (37-39). These same studies, however, demonstrate that DMFT scores in children from schools in fluoridated areas were 14-35 percent lower than in children from schools in nonfluoridated areas. Residence histories were not accounted for in these reports; however, in three other recent studies in New Zealand that did document residence history, mean DMFT and dmft scores were 29-42 percent lower in children from fluoridated areas $(33,40,41)$. Colquhoun's argument, weakened by the questions about his data, is unconvincing in light of the other recent evidence from New Zealand.

\section{Other Fluoride Issues}

The arguments raised by Diesendorf and Colquhoun question the effectiveness of fluoridation. Surprisingly little criticism of fluoridation in the 1980s has depended on the issue of civil rights or legality; an optimistic view would be that this is because the issue has been virtually exhausted. In an extensive review, Block (42) concluded that the legality of fluoridation had been well tested and confirmed in United States courts, and that future challenges to fluoridation were likely to be directed at health and environment. British courts have not dealt directly with the "individual freedoms" arguments; but the view of Lord Avebury, chairman of the Parliamentary Human Rights Committee, is that they are invalid (43).

Another long-term focus of fluoridation's opponents, the alleged hazards of fluoride to human health, received a great deal of attention during the $1970 \mathrm{~s}$ $(44,45)$. This issue too has been somewhat muted in recent years, perhaps since the 1983 Strathclyde court decision in Scotland, though some concerns have been aired recently about supplemental uses of fluoride rather than water fluoridation. Smith's reviews, for example, of the potential dangers of excessive use of fluorides $(46,47)$ do not differ much in tone from cautionary papers in the medical and dental literature $(48,49)$. Smith's principal concern is with dental providers who 
may be applying or prescribing fluoride products in a "... reckless and uncontrolled manner" rather than with water fluoridation. He stated:

... despite a number of well-publicized claims to the contrary, there is no generally accepted evidence that anyone has been harmed by drinking artificially fluoridated water. Nevertheless, the margin between a safe daily intake of fluoride and a potentially harmful one is narrow (46).

Smith's reports highlight some fundamental problems in fluoride research. For example, there has never been an optimum fluoride intake established chiefly because of the difficulties of research into fluoride physiology and metabolism in humans. Hodge (50) and Ophaug et al. (51) accept that the optimum intake of fluoride in humans is $0.05-0.07 \mathrm{mg} / \mathrm{kg}$ body weight per day, a finding attributed to Farkas and Farkas (52). Smith goes so far as to call it the ". . generally recommended required daily dose of fluoride . . .," which is probably going further than many dental researchers would. But Farkas and Farkas arrived at their figure (they gave it as $0.06 \mathrm{mg} / \mathrm{kg} /$ day) from a range of personal opinions, not all of them from sources universally accepted as expert. These figures are thus best estimates, rather than the results of experimental studies.

\section{Discussion}

The gap in caries experience between residents of fluoridated and nonfluoridated areas is still evident, though it apparently has narrowed. The 50-60 percent differences in DMF values, reported consistently in earlier studies among both adults $(53,54)$ and children $(55)$, have not been seen in most recent reports (37-39,56-59), though one assessment of five-year-old British children did find a difference of this magnitude (60). A provocative though analytically incomplete report from British Columbia (61) suggested that the caries decline in that mostly nonfluoridated province was greater than that seen in some Canadian provinces with higher levels of fluoridation. Thylstrup et al. (62) argued that the rate of caries decline in nonfluoridated areas in Denmark has been much greater than in the country's naturally fluoridated areas. But the "diminishing returns" phenomenon, meaning that there was more room for initial improvement in the nonfluoridated than in the fluoridated areas and that subsequent improvement in nonfluoridated areas will be slower, could have influenced the observed trends. And as we discussed previously (2), rapid population shifts in the study areas threatened the validity of the data used by Thylstrup et al.

Lest these reports be seen by some to devalue water fluoridation, a sharp reminder came with data from Wick, Scotland, which fluoridated its water supply in 1969 and ceased fluoridating in 1979. By 1984, 5-6-yearold children had dmfs scores that were 39.6 percent higher than in 1979 , and there were 10.1 percent fewer caries-free children (63).

A narrowing in caries experience between fluoridated and nonfluoridated areas should not be surprising in view of the growth of different fluoride vehicles, especially toothpastes, since 1970 . When drinking water constituted the only source of fluoride, differentials were proportionately greater than since fluoride has become available from toothpastes, rinses, professional treatments, and to an unknown extent from food processed with fluoridated water. Anticaries effects accrue from the intraoral environment, which results from frequent infusions of low-concentration fluoride, rather than as a function of the vehicle by which fluoride is introduced. It is sufficient to say that current understanding of how fluoride works, when added to the epidemiologic data, leads to the conclusion that fluoride (regardless of its delivery vehicle) is a prime factor in the caries decline.

The nature of the fluoride vehicle, however, does become a primary issue when communitywide effectiveness, costs, and the political issues inherent to public health are under consideration. It is generally agreed that water fluoridation is the most efficient caries-preventive method in developed countries with municipal water supplies, and because individual compliance is not a factor, it is probably the most effective as well. The issues of effectiveness and efficiency, as defined by the World Health Organization (64), need to be considered separately when public health policy is being established.

In summary, no new scientific evidence has emerged during the 1980 s to challenge the established safety and efficacy of water fluoridation. Fluoride in several delivery forms continues to play a major role in the caries decline among children. While further research should be directed at answering questions about optimum amounts of fluoride and the efficiency and practicality of various delivery methods, current practice has clearly been safe and effective.

\section{References}

1. MNeil DR. The fight for fluoridation. New York: Oxford University Press, 1957.

2. Beltran ED, Burt BA. The pre- and posteruptive effects of fluoride in the caries decline. J Public Health Dent 1988;48(4):233-40.

3. Diesendorf $M$. The mystery of declining tooth decay. Nature 1986 Juj;322:125-9.

4. Colquhoun ]. Disfiguring dental fluorosis in Auckland, New Zealand. Fluoride 1984 Oct;17:234-42.

5. Colquhoun J. New evidence on fluoridation. Soc Sci Med $1984 ; 19: 1239-46$.

6. Colquhoun J. Influence of social class and fluoridation on dental health. Community Dent Oral Epidemiol 1985 Feb;13:37-41.

7. Colquhoun J. Fluoridation in New Zealand: new evidence. Part One. Am Lab 1985 May;17:66-9,71-2

8. Colquhoun J. Fluoridation in New Zealand: new evidence. Part Two. Am Lab 1985 Jun;17:98,100-4,107-9.

9. Colquhoun J, Mann R. The Hastings fluoridation experiment: science or swindle? The Ecologist 1986;16:243-8.

10. Lawson JS, Brown JH, Oliver TI. The dramatic improvement in dental health of schoolchildren in the Northern Metropolitan Region of New South Wales. Med J Aust 1978 Feb;1:124-5.

11. Barnard PD. Dental survey of state schoolchildren in New South Wales. NHMRC Spec Rep Series 8:30-43. Canberra: National Health and Medical Research Council, 1956.

12. Carr LM. Fluoridation in Canberra. Part I. Prefluoridation data: dental caries and mottled enamel. Aust Dent J 1966;11:248-57

13. Burton VJ, Rob MI, Craig GG, Lawson JS. Changes in the caries 
experience of 12-year-old Sydney schoolchildren between 1963 and 1982. Med J Aust 1984 Mar 31;140:405-7.

14. Sutton PRN. Caries in Sydney schoolchildren. Med J Aust 1984 Sept;141:394-5.

15. Barnard PD, Clements FW. Oral health care in Australia. Int Dent J 1976 Sept;26:320-6

16. Dean HT, Arnold FA Jr, Jay P, Knutson JW. Studies on mass control of dental caries, through fluoridation of the public water supply. Public Health Rep 1950 Oct;65:1403-8.

17. Hardwick JL, Teasdale J, Bloodworth G. Caries increments over 4 years in children aged 12 at the start of water fluoridation. Brit Dent j 1982 Sept;153:217-22.

18. Kalsbeek H. Evidence of decrease in prevalence of dental caries in the Netherlands: an evaluation of epidemiological caries surveys on 4-6- and 11-15-year-old children, performed between 1965 and 1980. J Dent Res 1982 Nov;61(Spec Iss):1321-6.

19. Anderson RJ, Bradnock G, Beal JF, James PMC. The reduction of dental caries prevalence in English schoolchildren. J Dent Res 1982 Nov;61(Spec Iss):1311-6.

20. Burt BA. The future of the caries decline. J Public Health Dent 1985 Fall; $45: 261-9$

21. Levine RS. The action of fluoride in caries prevention; a review of current concepts. Br Dent J 1976 Jan;140:9-14.

22. Ericsson SY. Cariostatic mechanism of actions of fluorides: clinical observations. Caries Res [Suppl] 1977;11:2-23.

23. Wefel JS. Mechanisms of action of fluorides. In: Stewart RE, Barber TK, Trotman KC, Wei SHY, eds. Pediatric dentistry. St. Louis: CV Mosby, 1982:772-9.

24. Colquhoun J. The influence of social rank and fluoridation on dental treatment requirements. NZ Dent J 1977 Feb;73:146-8

25. Castaldi CR, Quigley W, Zacherl W. Fluoridation, dental health, and socioeconomic level [Abstract]. J Dent Res 1961:40:726.

26. Szwejda LF. Dental caries experience by race and socioeconomic level after eleven years of water fluoridation in Charlotte, North Carolina. J Public Health Dent 1962 Spring;22:91-8.

27. Carmichael CL, Rugg-Gunn AJ, French AD, Cranage JD. The effect of fluoridation upon the relationship between caries experience and social class in 5-year-old children in Newcastle and Northumberland. Br Dent J 1980 Sept;149:163-7.

28. Carmichael CL, French AD, Rugg-Gunn A], Furness JA. The relationship between social class and caries experience in fiveyear-old children in Newcastle and Northumberland after twelve years' fluoridation. Community Dent Health 1984 Mar;1:47-54.

29. Weddell JA, Klein AI. Socio-economic correlation in oral disease in six to thirty-six month old children. Am Acad Pedod 1981:3:306-20.

30. Hausen $\mathrm{H}$, Heinonen OP, Paunio $\mathrm{I}$. Caries in permanent dentition and social class of children participating in public dental care in fluoridated and nonfluoridated areas. Community Dent Oral Epidemiol 1981 Dec;9:289-311.

31. Hausen $H$, Milen A, Heinonen OP, Paunio I. Caries in primary dentition and social class in high and low fluoride areas. Community Dent Oral Epidemiol 1982 Feb;10:33-6.

32. Bradnock G, Marchment MD, Anderson RJ. Social background, fluoridation and caries experience in a 5-year-old population in the West Midlands. Br Dent J 1984;156:127-31.

33. Evans RW, Beck DJ, Brown H, Silva PA. Relationship between fluoridation and socioeconomic status on dental caries experience in 5-year-old New Zealand children. Community Dent Oral Epidemiol 1984 Feb;12:5-9.

34. Sutton PRN. Fluoridation; errors and omissions in clinical trials 2nd ed., Melbourne: Melbourne Univ Press, 1960.

35. Dunning JM. Deployment and control of dental auxiliaries in New Zealand and Australia. I Am Dent Assoc 1972 Sept;85:61826.

36. Friedman JW. The New Zealand School Dental Service: lesson in radical conservativism. J Am Dent Assoc 1972 Sept;85:618-26.

37. Hunter PBV. The prevalence of dental caries in 5-year-old children in 1977 and 1982. NZ Dent J 1984 Jan;80:14-6.

38. Hunter PBV. The prevalence of dental caries in 12- and 13-yearold New Zealand children in 1977 and 1982. NZ Dent J 1984 Jan;80:16-18.
39. Hunter PBV. The prevalence of dental caries in 8-and 9-vear-old New Zealand children. NZ Dent I 1985 Jan;81:23-5.

40. de Liefde B, Herbison GP. Prevalence of developmental defects of enamel and dental caries in New Zealand children receiving differing fluoride supplementation. Community Dent Oral Epidemiol 1985 Jun; 13:164-7.

41. Fergusson DM, Horwood LJ. Relationships between exposure to additional fluoride, social background and dental health in 7 year-old children. Community Dent Oral Epidemiol 1986 Feb;14:48-52.

42. Block LE: Antifluoridationists persist: the constitutional basis for fluoridation. J Public Health Dent 1986 Fall;46:188-98.

43. Avebury. Fluoridation and individual freedom. Br Dent I 1984 Apr $; 156: 277$

44. Waldbott GL, Burgstahler AW, McKinney HL. Fluoridation; the great dilemma. Lawrence, KS: Coronado Press, 1978.

45. Yiamouyannis J, Burk D. Fluoridation and cancer. Fluoride 1977 Jul; 10:102-23.

46. Smith GE. Toxicity of fluoride-containing dental preparations: a review. Science Total Env 1985;43:41-61.

47. Smith GE. Fluoride, the environment, and human health. Perspect Biol Med 1986 Summer;29:560)-72.

48. Leverett DH. Fluorides and the changing prevalence of dental caries. Science 1982 Jul;217:26-30

49. Heifetz SB, Horowitz HS. Amounts of fluoride in self-administered dental products: safety considerations for children. Pediatr 1986 Jun;77:876-81.

50. Hodge HC. The safety of fluoride tablets or drops. In: Johansen E, Taves DR, Olsen $T$, eds. Continuing evaluation of the use of fluorides. AAAS Selected Symposium no 11. Boulder, CO: Westview Press, 1979:253-74.

51. Ophaug RH, Singer L, Harland BF. Estimated fluoride intake of average two-year-old children in four dietary regions of the United States. J Dent Res 1980 Mav;59:777-81

52. Farkas CS, Farkas EJ. Potential effect of food processing on the fluoride content of infant foods. Science Total Env 1974 Jul;2:399405

53. Russell AL, Elvove E. Domestic water and dental caries, VII. A study of the fluoride-dental caries relationship in an adult population. Public Health Rep 1951 Oct;66:1389-401

54. Englander HR, Wallace DA. Effects of naturally fluoridated water on dental caries in adults. Public Health Rep 1962 Oct;77:887-93.

55. Newbrun E. Cost-effectiveness and practicality features in the systemic use of fluorides. In: Burt BA, ed. The relative efficiency of methods of caries prevention in dental public health. Ann Arbor: University of Michigan, 1979:33.

56. Brunelle JA, Miller A], Smith JI. DMFS in US children with and without lifelong exposure to water fluoridation [Abstract]. J Dent Res 1983;62(Spec Iss):203.

57. O'Hickey S, Pigott B. Dental caries experience of Dublin schoolchildren after 10 1/2 years of fluoridation. J Irish Dent Assoc 1983 Jan-Feb;29:5-8.

58. Klein SP, Bohannan HM. The first year of field activities in the National Preventive Dentistry Demonstration Program. Santa Monica: Rand pub no R-2536/1-RWI, 1979.

59. Jackson D, James PMC, Thomas FD. Fluoridation in Anglesey 1983: a clinical study of dental caries. Br Dent ] 1985 Jan:158:45-9.

60. Duxbury JT, Lennon MA, Mitropoulos CM, Worthington HV. Differences in caries level in 5-year-old children in Newcastle and North Manchester in 1985. Br Dent J 1987 Jun; 162:457-8.

61. Gray AS. Fluoridation, time for a ne'w base line? J Can Dent Assoc 1987 Oct:53:763-5.

62. Thylstrup A, Bille J, Bruun C. Caries prevalence in Danish children living in areas with low and optimal levels of natural water fluoride. Caries Res 1982;16:413-20.

63. Stephen KW, McCall DR, Tullis II. Caries prevalence in northern Scotland before, and 5 years after, water fluoridation. Br Dent J 1987 Nov; $163: 324-6$

64. World Health Organization. Statistical indicators for the planning and evaluation of public health programmess. Geneva: WHO Terch Rep Series no 472, 1971. 